\title{
Survey of the Relationship Between Demographic Characteristics and Organizational Citizenship Behavior in Nurses in Hamadan Educational Centers
}

\author{
Amir Sadeghi ${ }^{1,2}$, Mehrdad Maleki Jamasbi ${ }^{3 *}$, Hiva Azami ${ }^{4}$, \\ Manoochehr Karami ${ }^{5}$, Zahra Marziyeh Hassanian ${ }^{6}$
}

1. Associated Professor, Department of Nursing, Mother and Child Care Research Center, Faculty of Nursing and Midwifery

2. Department of Nursing, Chronic Disease Research Center (Home Care), Hamadan University of Medical Sciences, Hamadan, Iran

3. Instructor, Department of Nursing, Faculty of Nursing and Midwifery, Hamadan University of Medical Sciences, Hamadan, Iran

4. Instructor, Department of Nursing, Faculty of Nursing and Midwifery Hamadan University of Medical Sciences, Hamadan, Iran

5. Associate Professor, Department of Epidemiology, Faculty of Public Health, Hamadan University of Medical Sciences, Hamadan, Iran

6. Assistant Professor, Department of Nursing, School of Nursing and Midwifery, Hamadan University of Medical Sciences, Hamadan, Iran

\begin{tabular}{|c|c|}
\hline Article Info & ABSTRACT \\
\hline $\begin{array}{l}\text { Received: 2019/01/28; } \\
\text { Accepted: 2019/06/03; } \\
\text { Published Online: 2019/08/28 } \\
\text { dol } \underline{\mathbf{1 0 . 3 0 6 9 9 / s j h n m f . 2 7 . 5 . 3 2 6}}\end{array}$ & $\begin{array}{l}\text { Introduction: Nurses are the most effective pillars of the hospital to improve the } \\
\text { quality of services. Their organizational citizenship behaviors are an important factor } \\
\text { for improving patient's nursing care. Organizational Citizenship Behaviors (OCB) can } \\
\text { prevent additional system costs. The present study was an attempt to determine the } \\
\text { relationship between demographic characteristics and OCB of nurses in Hamadan } \\
\text { educational centers. }\end{array}$ \\
\hline
\end{tabular}

Original Article

Use your device to scan and read the article online

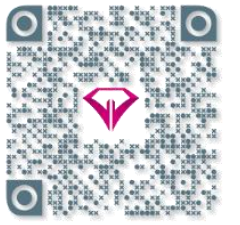

Methods: This descriptive-analytic correlational study was conducted in 2016-17. The sample was 200 nurses selected from five educational centers by stratified random sampling method. Data gathering tool were Demographic Information and Organizational Citizenship Behavior of Podsakoff Questionnaires. Data were analyzed by SPSS 21 and using descriptive and analytical statistics (T-test, ANOVA and Pearson correlation coefficient).

Results: The results showed that a relatively favorable level of nurses' OCB. There were statistically significant relationship between OCB of nurses with age and work experience respectively $(\mathrm{r}=0 / 20$ and $P<0 / 005)$ and $(P<0 / 029$ and $\mathrm{r}=0 / 16)$. Mean score of Courtesy was $4.03 \pm 0.5$, Conscientiousness $4.0 \pm 0.5$, Magnanimity $3.83 \pm 0.4$, Civic Virtue 3.33 \pm 3.8 , Altruism $3.83 \pm 0.4$ and the mean score of OCB was $3.8 \pm 0.3$.

Conclusion: Organizational citizenship behavior of nurses increases with increasing their age and work experience. Therefore, to take advantage of the OCB in hospitals, intensive attention should be paid to training younger nurses and supporting them.

Keywords: Demography, Organizational citizenship behavior, Nurses, Education department

Corresponding Information:

Mehrdad Maleki Jamasbi, Department of Nursing, Faculty of Nursing and Midwifery, Hamadan

University of Medical Sciences, Hamadan, Iran. E-mail: mehrdad.malekiৎ9@gmail.com

Copyright $@$ (2019, This is an original open-access article distributed under the terms of the Creative Commons Attribution-noncommercial 4.0 International License which permits copy and redistribution of the material just in noncommercial usages with proper citation.

\section{How to Cite This Article:}

Sadeghi A, Maleki Jamasbi M, Azami H, Karami M, Marziyeh Hassanian Z. Survey of the Relationship Between Demographic Characteristics and Organizational Citizenship Behavior in Nurses in Hamadan Educational Centers. Avicenna J Nurs Midwifery care. 2019; 27 (5) :326-334 


\section{بررسى رابطه ويزگَى هاى دموكرافيك با رفتار شهروندى سازمانى يرستاران مراكز آموزشى درمانى همدان

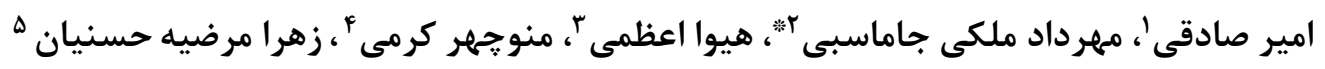

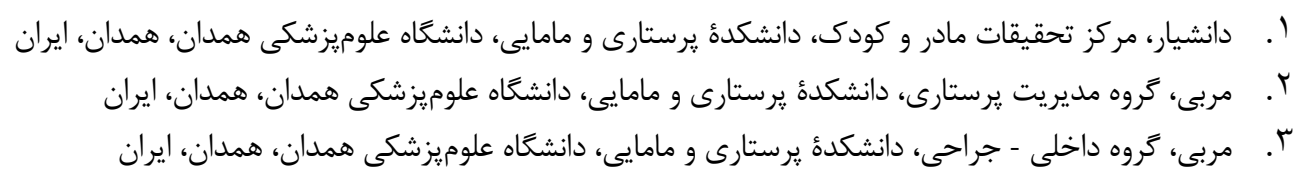

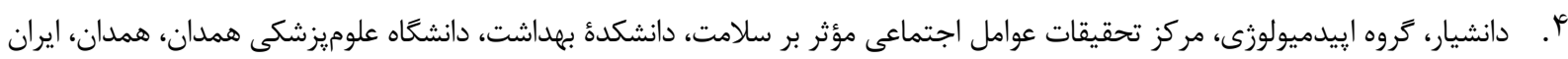

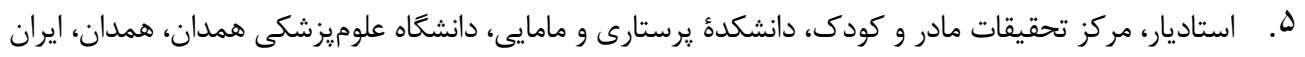

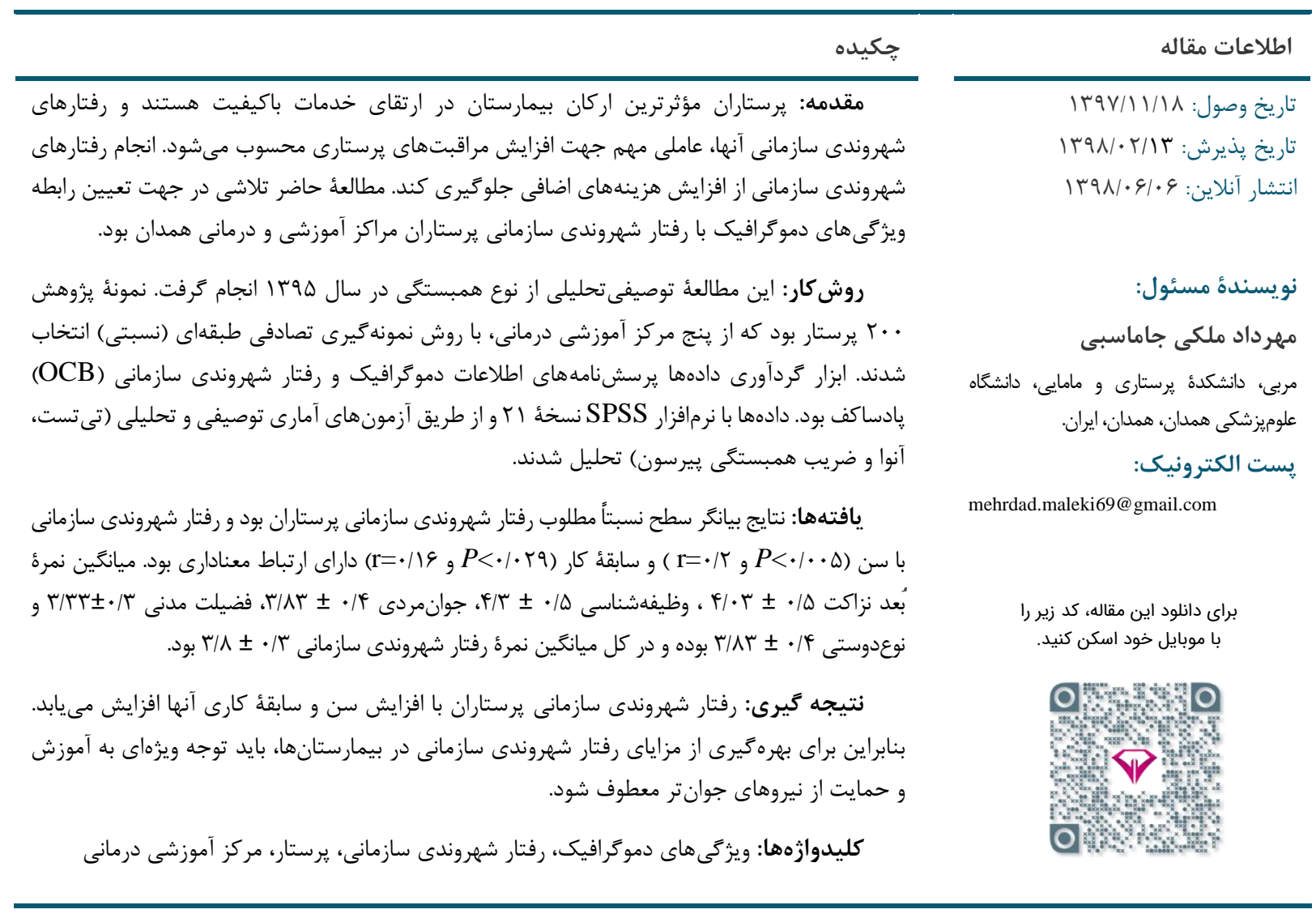

\section{مقد مه}

بيمارستان ها همجون يك واحد صنعتى متشكل از عوامل توليد

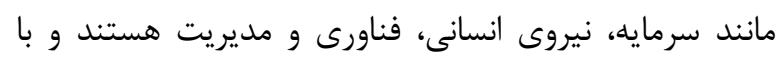
استفاده از تسهيلات ويزه، جهت توليد محصولى به نام ندئ حفظ،

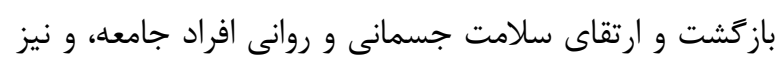

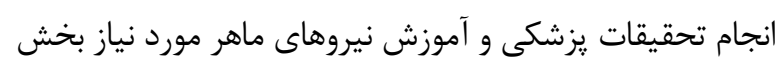
بهداشت و درمان، نقش اساسى ايفا مى كنند [ه] به عنوان مهممترين موسسة بهداشتى و يايهاى اساسى در اولين سطح ارجاع در ارائٔ مراقبتهاى بهداشتى و دوريه درانى به حساب

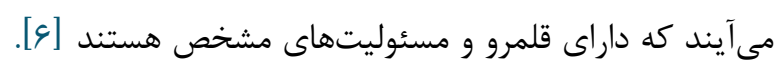

جهان معاصر با سرعتى شخفتانگيز در حال تغيير و تحول

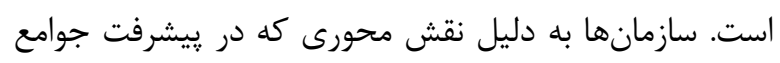

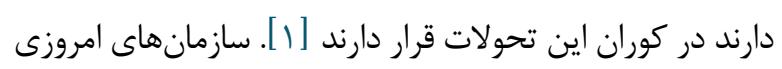
اخر قادر به انطباق خود و نيروهايشان با اين تحولات نباشند

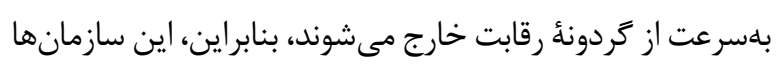
براى ادامٔ حيات خود و ارائٔ مراقبتهاى باكيفيت بايد نقاط

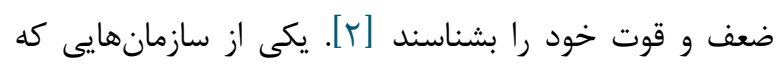

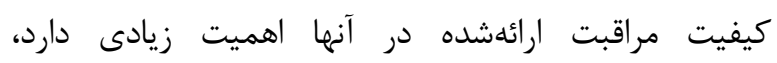

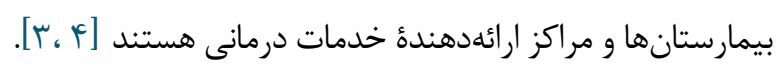


سازمانى بر كيفيت ارائٔ خدمات ارائه شده توسط يرستاران دارد،

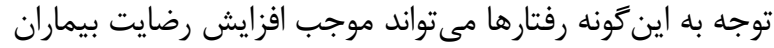

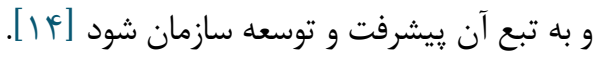
صرف زمان براى رفتارهاى شهروندى سازمانى باعث خواهد شد يرستاران زمان محدود كارى خود را به طور كارآمدترى برى تخصيص داده و به تعادل كار - خانواده متناسبى دست يابند، كه كها

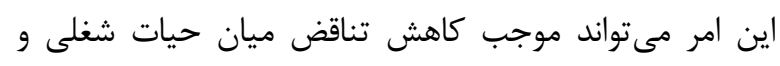

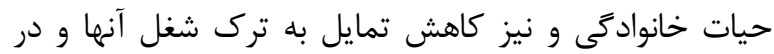

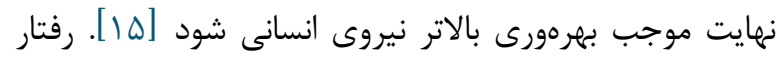

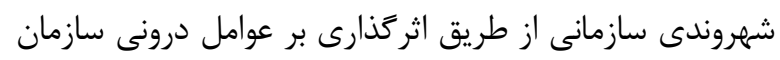

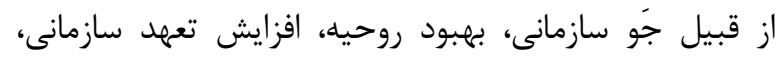

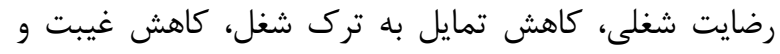

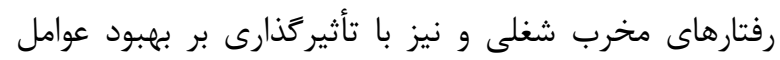

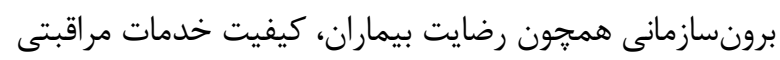

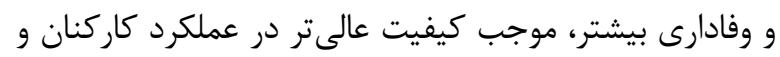

سازمان خواهد شد [19].

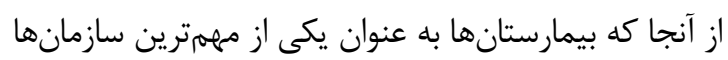

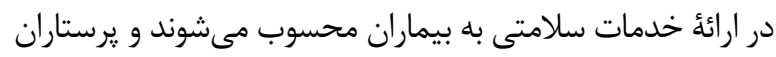

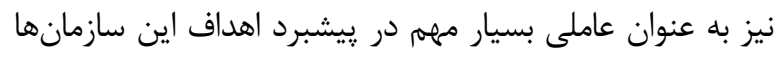

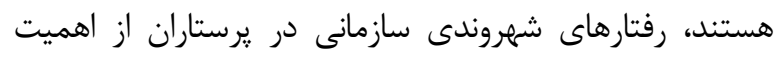

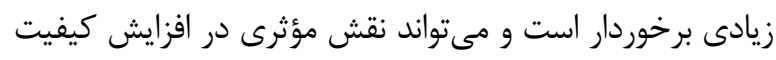
ارائُٔ مراقبت يرستارى در حيطههاى بالينى، روانى، و اجتماعى بهانه

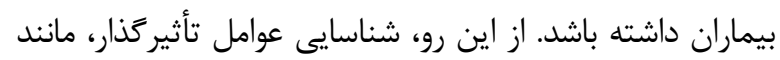

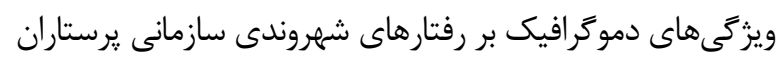

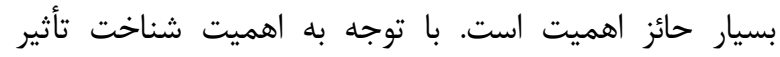
ويزگى هاى دموكر افيك بر رفتارهاى شهروندى سازمانى يرستاران،

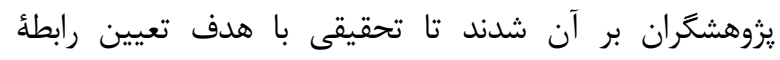

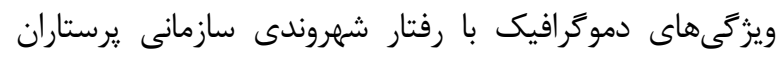
مراكز آموزشى درمانى همدان در سال هوبا إنجام دهند.

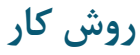

يزوهش حاضر يك مطالعه توصيفى تحليلى از نوع همبستگى

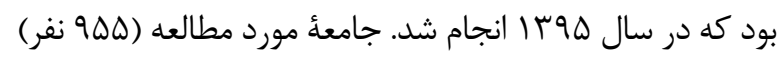

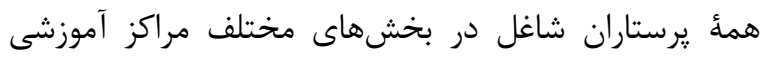

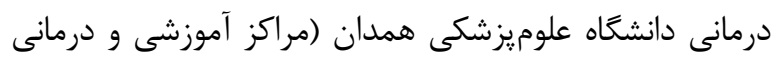

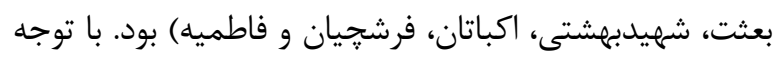

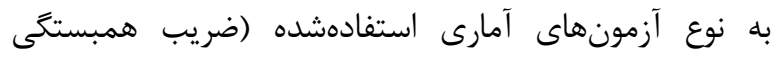

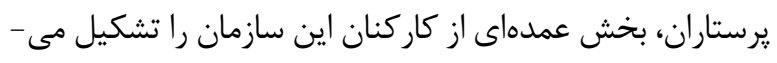

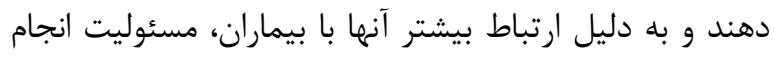

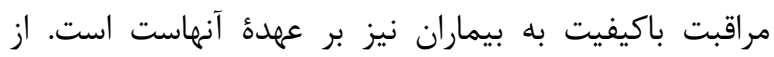

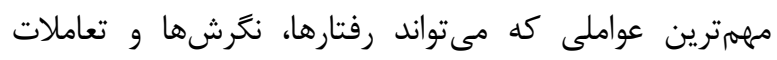

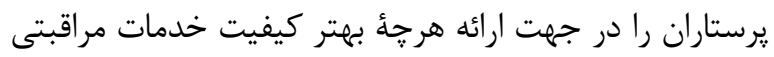

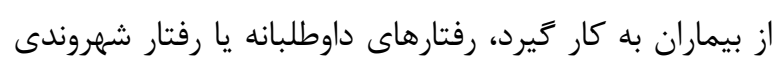

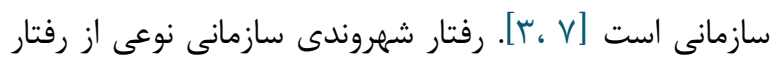
است كه فراتر از رفتارهاى رسمى تعريفشده توسط سازمانها

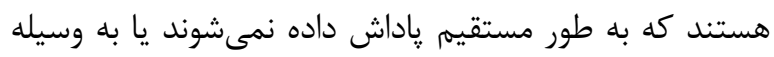

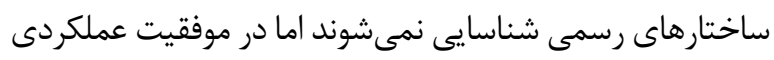

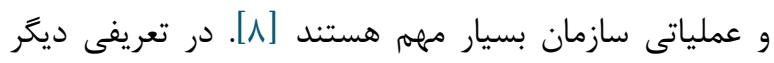

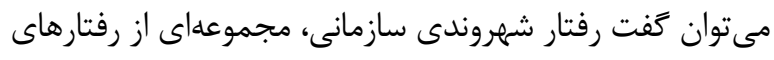

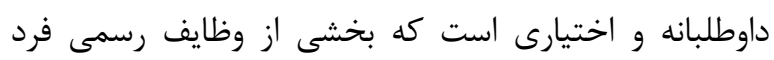

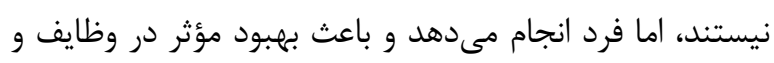

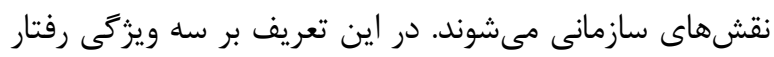

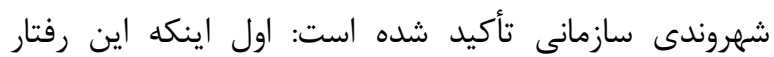

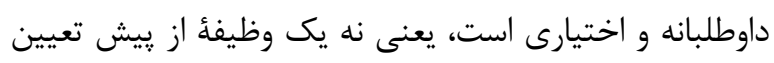

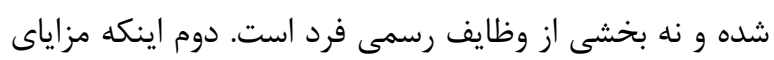

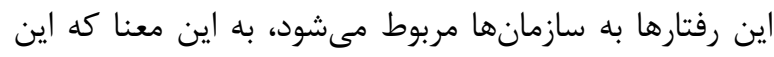

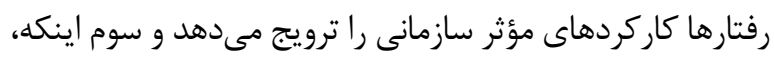

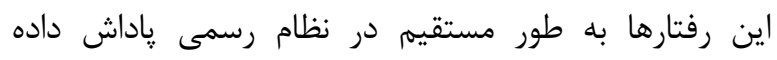

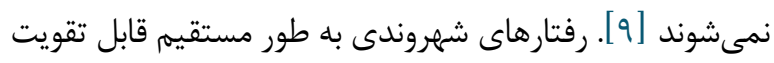

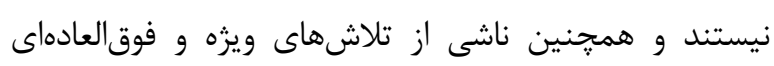

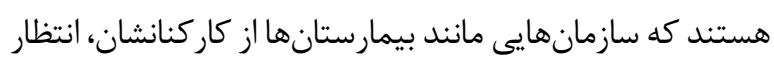

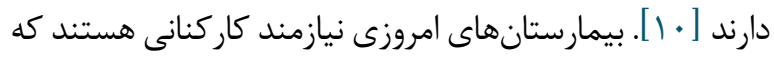

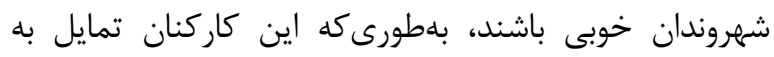

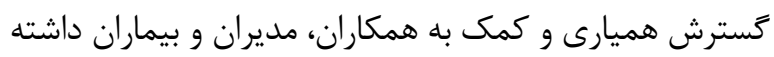

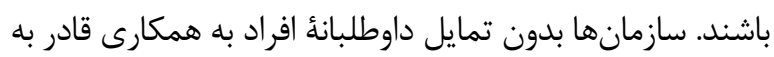
رشد و توسعه خود نيستند و موضوع مههم در اين ميان نيز تمايز

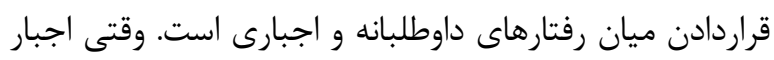

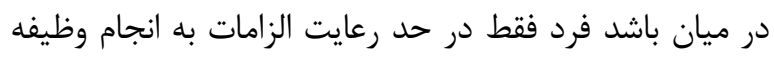

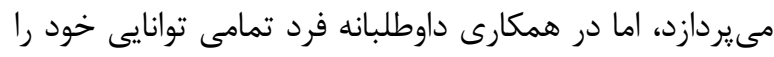

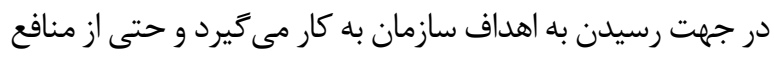

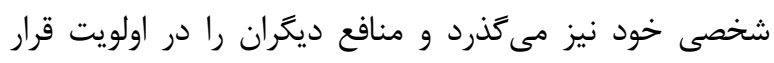

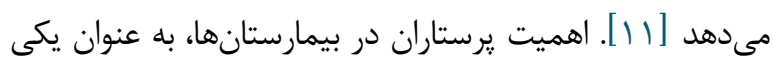

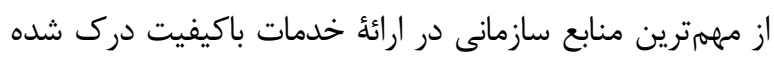

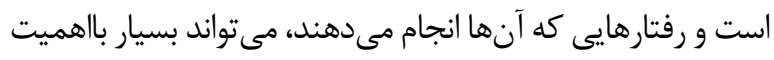

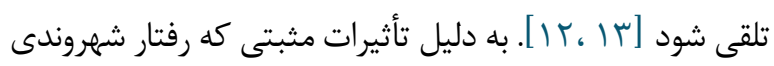


هر فرد در كمك,رانى به ديخر افراد سازمان است كه هدف عمده آن انجام بهتر وظايف است.

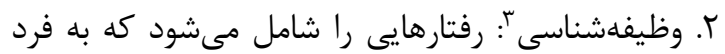
اجازه مىدهد وظايف خود را بالاتر از حد انتظار انجام دهد و در انجام وظايف دروننقشى عملكرد مطلوبى نشان مىدهد. r. جوانمردى +أ: داشتن تمايل از طرف كارمند براى تحمل

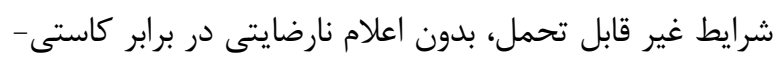
هاى واقعى. (- مان. f. ادب و مهربانى ها: رفتارهايى كه از بروز مشكل جلوگيرى مى كند، مانند اجتناب از بروز مشكل براى همكاران يا مشورت ييش از اقدام.

ه. فضيلت مدنى ؟ , رفتارى كه نشان مى إدهد يك كارمند به حيات سازمان اهميت مى دهد و در جهت آن مسئولانه شركت مت مدئ

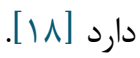

اين يرسشنامه را Podsakoff و همكاران ساختند و پايايى درونى اين ابزار را براى كل يرسشنامه، | | • • و براى ابعاد

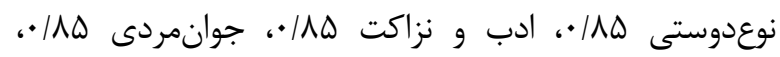

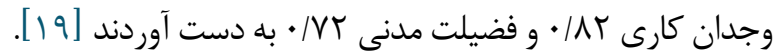

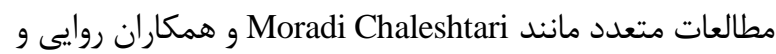

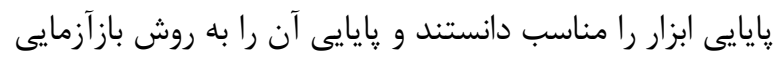

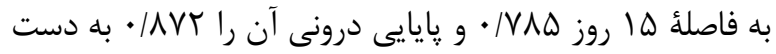
آوردند [ [1]. Naami و Shokrkon يايايى اين ابزار را براى رفتار

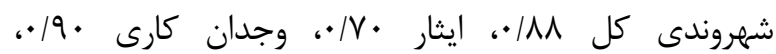

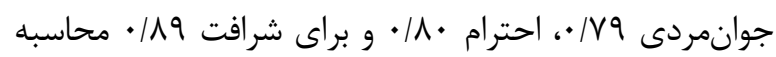

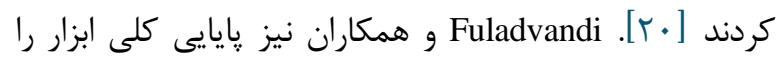

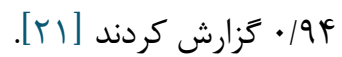
روايى صورى و محتوايى يرسشنامه به تأييد اساتيد هيئت علمى مديريت يرستارى دانشكدة ڤرستارى و مامايى همدان

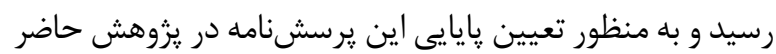

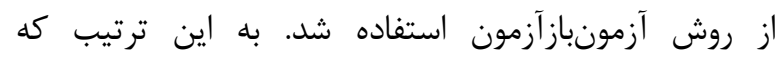

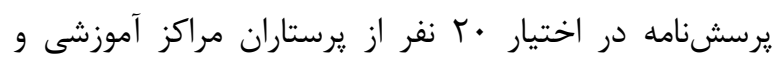

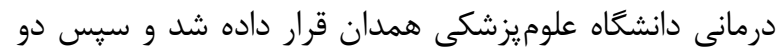
هفته بعد دوباره همان يرسشنامه در اختيار همان افراد قرار

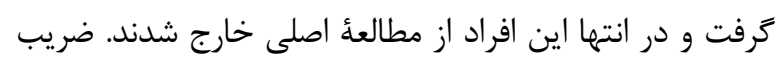

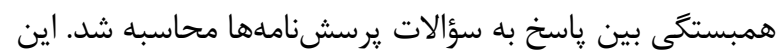

\footnotetext{
4. Sportsmanship

5 . Courtesy

6 . Civic virtue
}

ييرسون، آزمون آمارى تى و آنووا) و با نرمافزار جى ياور ا.ب با

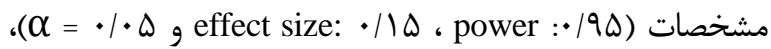
· · . نفر به روش تصادفى طبقهاى از نوع نسبتى به عنوان نمونه

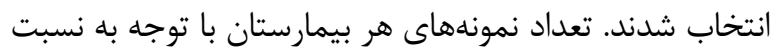

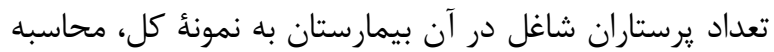

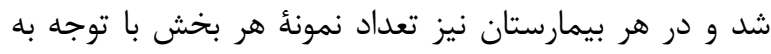
نسبت تعداد يرسنل بخش به نمونهُ اختصاص يافته به بيمارستان،

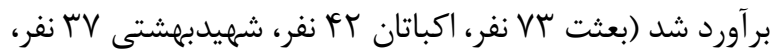
فرشجيان سب نفر، و فاطميه ها نفر). در آخر، نمونه روش تصادفى ساده انجام شد. معيارهاى ورود به مطالعه عبارت

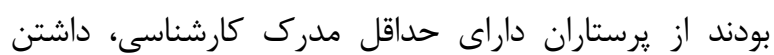

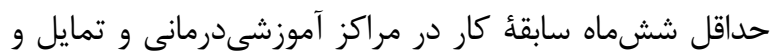
رضايت شركت كنندكان به شركت در يزوهش و معيارهاى خروج از مطالعه، عدم تمايل به شركت در مطالعه و يركردن ناقص و ودرئ مخدوش يرسش مشامهها بود.

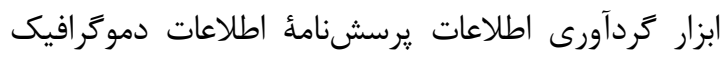
(سن، جنس، وضعيت تأهل، سطح تحصيلات، سابقه كار) و

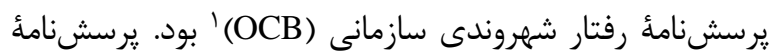

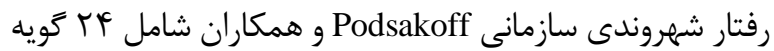

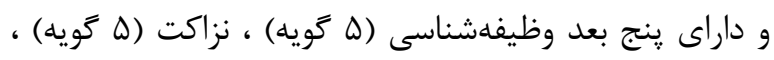

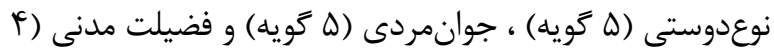

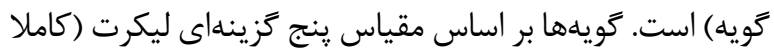

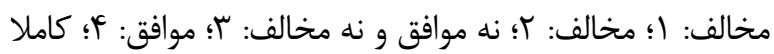

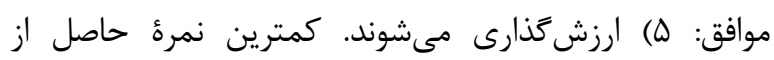

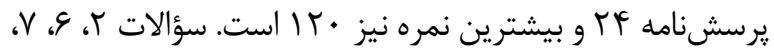

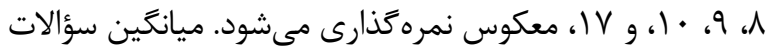
هر بُعد از يرسشنامه محاسبه شد و سيس رفتار شهروندى سازمانى يرستاران با معيار استاندارد زير تفسير مىشود:

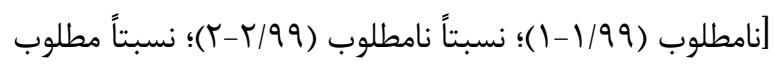

[l V]

به طور خلاصه ابعاد پنج ₹انهُ رفتار شهروندى سازمانى شامل موارد زير است: - ماسه ا. نوعدوستى זّ: اين بُعد با كمك داوطلبانه به افراد

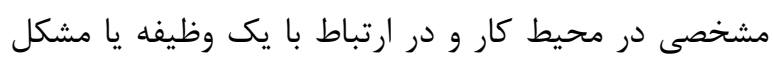
سازمانى مرتبط است و شامل مجموعهاى از رفتارهاى آخاهانئ

${ }^{1}$ Organizational Citizenship Behavior (OCB)

2 . Altruism

3 . Conscientiousness 
سازمها با ميانغين نرم يرسشنامه مقايسه شد. سطح معنى دارى در اين مطالعه ه• • • در نظر خرفته شد.

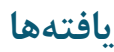

نتايج نشان داد كه جنسيت • + درصد از يرستاران مورد

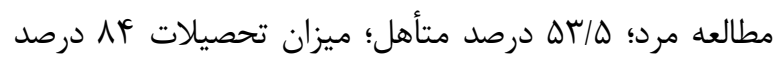

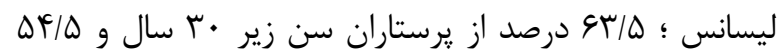
درصد از يرستاران كمتر از ه سال سابقه كار داشتند. ميانكين

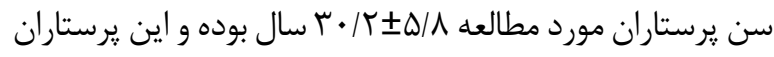

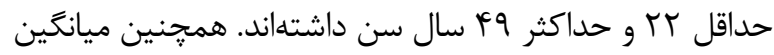

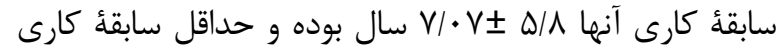

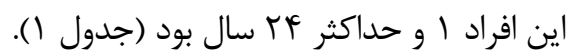

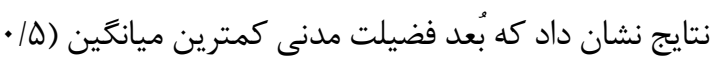

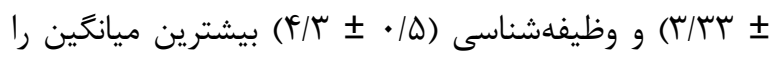

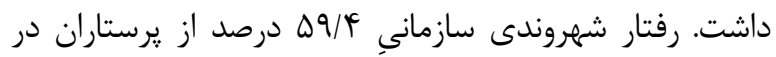

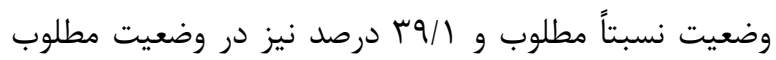

$$
\text { قرار داشت (جدول r). }
$$

نتايج نشان داد كه هرجند ميانگَين رفتار شهروندى سازمانى يرستاران مرد، داراى مدرى كارشناسى ارشد و متأهل بالاتر بود،

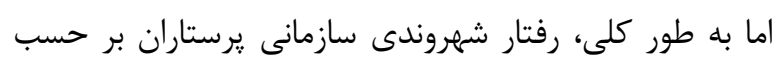

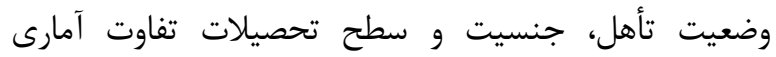

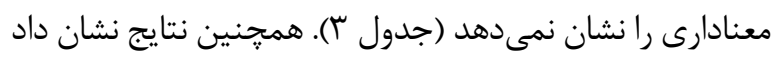

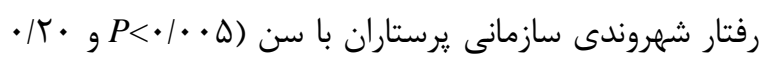

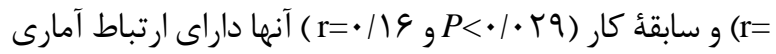

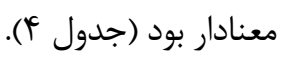

ضريب در ياسخكويى به سؤالات يرسشنامئ رفتار شهروندى

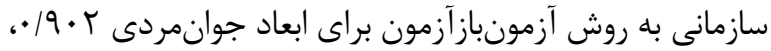

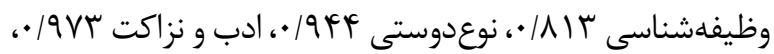

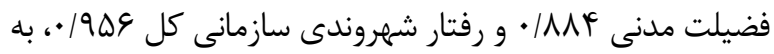

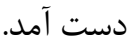
يس إز اخذ مجوز از معاونت تحقيقات دانشكاه و كميته اخلاق و با مراجعهُ حضورى به محل كار، يرسشنامه آنها به همراه

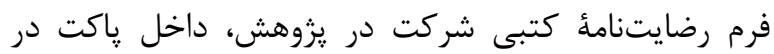
اختيار شركت كنندكان قرار كرفت، توضيحات لازم به ايشان

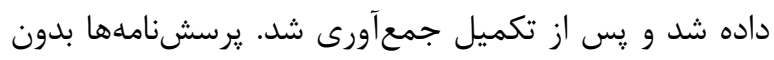

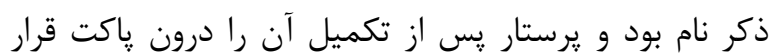

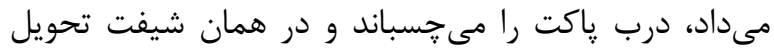

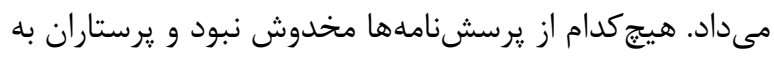
همأ سؤالات ياسخ داده بودند. دادهاى حاصل از يرسشنامه كد نذارى شده و سيس وارد نرمافزار SPSS نسخة الب SPSS Inc., Chicago, Ill., USA)

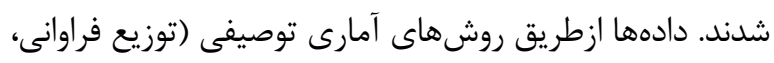
ميانكين و انحرافمعيار) و روشهاى آمارى تحليلى (ضريب آنداني همبستَى ييرسون، آزمون تى تست و آنووا) تحليل شدند. براى (ضرى

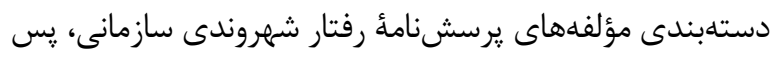

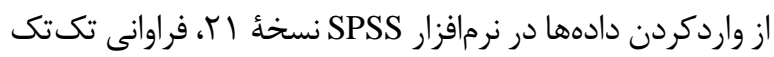
سؤالات هر مؤلفه محاسبه شد، سيس بيشترين و كمترين

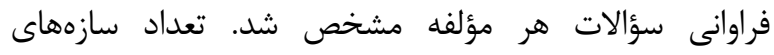

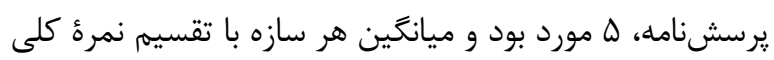

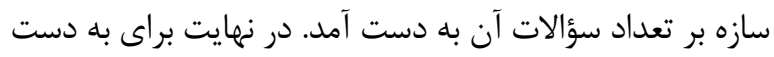

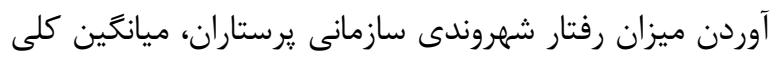

جدول ا . توزيع فراوانى مطلق و نسبى يرستاران بر حسب مشخصات دموكرافيك آنها

\section{فراوانى (درصد)}

$\Lambda \cdot(\boldsymbol{l} \cdot)$

$\mid r \cdot(9 \cdot)$

१५ (₹\&/Q)

$1 \cdot V(\Delta r / \Delta)$

$19 \wedge(\wedge F)$

re (19)

$\operatorname{ITV}(\Phi / / \Delta)$

\section{دسته ها}

مرد

زن

مجرد

وضعيت تأهل

متأهل

ليسانس

ميزان تحصيلات

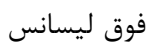

$r \cdot \geq$

\section{متغير}

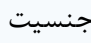

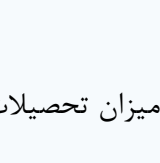

سن 
امير صادقى و همكاران آس آم

\begin{tabular}{|c|c|c|}
\hline فراوانى (درصد) & دسته ها & متغير \\
\hline$\Delta T(T \&)$ & rו-rᄉ & \multirow{7}{*}{ سابقهُ كارى } \\
\hline IV $(\Lambda / \Delta)$ & $r q-q v$ & \\
\hline$F(r)$ & $\forall \wedge \leq$ & \\
\hline $1 \pi \cdot(9 \Delta)$ & $v \geq$ & \\
\hline$F V(Y T / Q)$ & $1-10$ & \\
\hline IV $(\Lambda / \Delta)$ & $19-r r$ & \\
\hline$\varphi(r)$ & $r Y \leq$ & \\
\hline$r \cdot(1 \cdots)$ & & جمع \\
\hline
\end{tabular}

\begin{tabular}{|c|c|c|c|c|c|}
\hline تفسير & حداكثر & حداقل & ميانكين و انحرافمعيار & ابعاد شاخص & شاخص \\
\hline نسبتاً مطلوب & $F / \Lambda$ & $r / 9$ & $\cdot \pm \Lambda r / r / \varphi$ & جوانمردى & \multirow{6}{*}{ رفتار شهروندى سازمانى } \\
\hline نسبتاً مطلوب & $\Delta$ & $r$ & 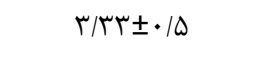 & فضيلت مدنى & \\
\hline مطلوب & $\Delta$ & $r / 4$ & $r / r \pm \cdot / \Delta$ & نزاكت & \\
\hline نسبتاً مطلوب & $\Delta$ & $r / \mathcal{E}$ & $r / \Lambda r \pm \cdot / \kappa$ & نوعدوستى & \\
\hline مطلوب & 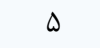 & $r / 9$ & $F / r \Psi \pm \cdot / Q$ & وظيفهشناسى & \\
\hline نسبتاً مطلوب & $F / V$ & $r / \Lambda$ & $r / \Lambda V \pm \cdot / r$ & كل & \\
\hline
\end{tabular}

جدول r. مقايسةُ رفتار شهروندى سازمانى يرستاران بر حسب جنسيت، سطح تحصيلات و وضعيت تأهل (آزمون ANOVAوT test )

\begin{tabular}{|c|c|c|c|c|c|c|c|c|}
\hline معنادارى & Df2 & Df1 & $\mathbf{F}$ & $\mathbf{t}$ & تعداد & انحرافمعيار & كروه ها & نام متغير \\
\hline \multirow{2}{*}{$\cdot / 099$} & \multirow{2}{*}{ - } & \multirow{2}{*}{199} & \multirow{2}{*}{$\cdot / \pi \Lambda$} & \multirow{2}{*}{$1 / 4 \Delta V$} & $\wedge \cdot$ & $q \uparrow / V \wedge \pm q / \uparrow \wedge$ & مرد مرد & \multirow{2}{*}{ جنسيت } \\
\hline & & & & & $1 r$. & $q \Gamma / \wedge q \pm Q / r r$ & زن & \\
\hline \multirow{3}{*}{.$|9| 4$} & \multirow{3}{*}{ - } & \multirow{3}{*}{199} & \multirow{3}{*}{$\cdot / \pi \Delta$} & \multirow{3}{*}{$-1 / \Delta 9$} & 191 & $q \Upsilon / \backslash \pm 9 / r)$ & كارشناسى & \multirow{3}{*}{ سطح تحصيلات } \\
\hline & & & & & rt & $Q \varphi / \cdot r \pm 1 \cdot / r r$ & كارشناسى ارشد & \\
\hline & & & & & $\wedge \Lambda$ & $91 / \Delta F \pm q / \Delta G$ & مجرد & \\
\hline \multirow[t]{2}{*}{$\cdot \mid 9 \wedge \Delta$} & \multirow[t]{2}{*}{190} & \multirow[t]{2}{*}{$r$} & \multirow[t]{2}{*}{ r/qTr } & \multirow[t]{2}{*}{-} & 1.9 & $Q \Delta / r \Lambda \pm \Lambda / V \varphi$ & متأهل & \multirow[t]{2}{*}{ وضعيت تأهل } \\
\hline & & & & & $r$ & $q 4 / \cdot . \pm \mid \Lambda / q \Lambda$ & مطلقه & \\
\hline
\end{tabular}


جدول F. نتايج آزمون همبستكى يِيرسون به منظور بررسى ارتباط ويزگى هاى دموكر افيك سن و سابقهُ كار با رفتار شهروندى سازمانى

متغير

بحث

در ارتباط نبود و فقط با سطح تحصيلات مرتبط بود كه آن هم به صورت عكس ززارش شده است؛ بدين معنا كه با افزايش سطح تحصيلات افراد، ميزان رفتار شهروندى سازمانى آنها كمتر

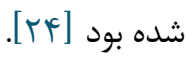

\section{نتيجة نهايى:}

نتايج نشان دادند كه رفتار شهروندى سازمانى يرستاران بيمارستانهاى آموزشى و درمانى همدان در سطح نسبتاً

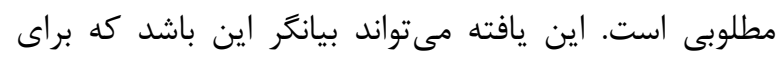

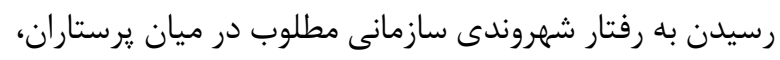

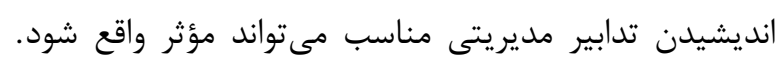

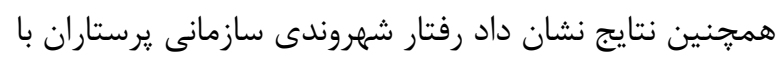

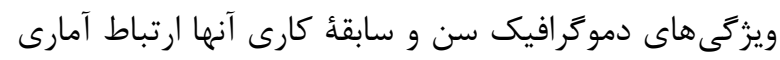
مثبت و معنادارى دارد. بدين صورت كه با افزايش سن و به تبع آن سابقهُ كارى يرستاران، رفتار شهروندى سازمانى آنها

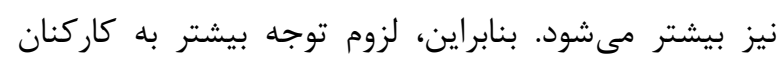

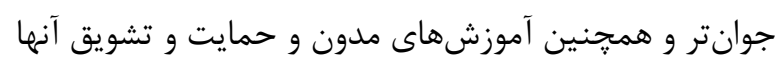
مىتواند باعث درونىسازى اين رفتارها در آنها شود و و با مديا بهره ميرى از اين آموزشها در آينده شاهد افزايش و وفين

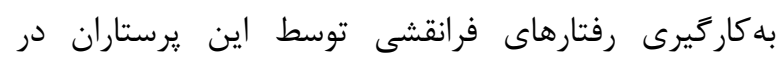

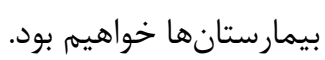

\section{سياسگزارى}

اين مقاله حاصل ياياننامئ دانشجويى مقطع كارشناسى

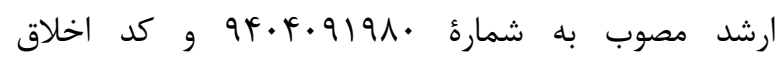

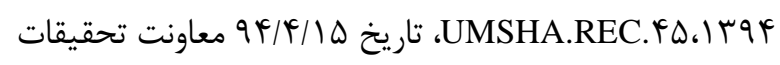
و فناورى دانشخاه علوميزشكى همدان است. يزوهشگران بر

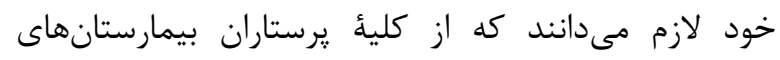
آموزشى درمانى دانشعاه علوميزشكى همدان كه در اجراى اين يزوهش همكارى داشتند، كمال تشكر و قدردانى كند.
اين مطالعه با هدف تعيين رابطهُ ويزگى هاى دموگرافيك با رفتار شهروندى سازمانى يرستاران مراكز آموزشى درمانى همدان

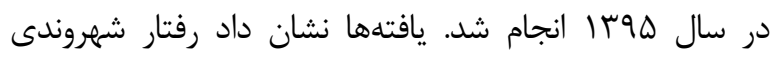

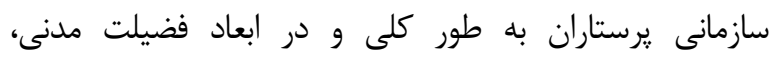

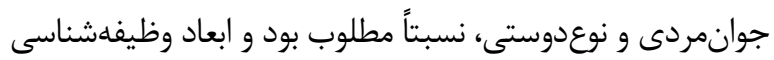

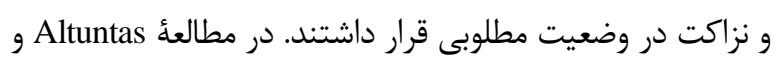

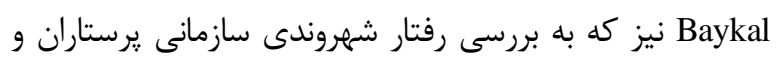

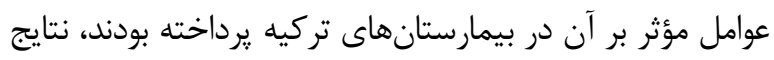

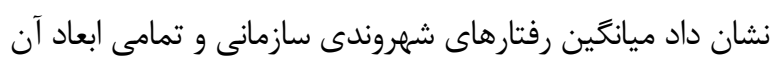
از ميانخين نُرم يرسشنامه بالاتر بود و در سطح نسبتاً مطلوب قرار داشت [ (1 ]]. دليل بالا بودن رفتار شهروندى سازمانى در مطالعئ حاضر را مىتوان به ماهيت حرفهاى يرستاران مربوط دانست. از آنجا كه يرستاران در تماس مداوم با بيماران هستند، دائماً در بر مريت جهت بهبود وضعيت روحى و جسمى بيماران تلاش مى كنند و اين امر مستلزم آنست كه از رفتارهاى فرانقشى مانند رفتار شهروندى سازمانى بالايى برخوردار باشند.

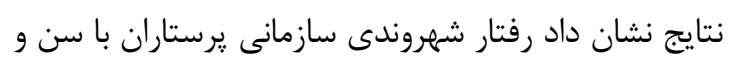

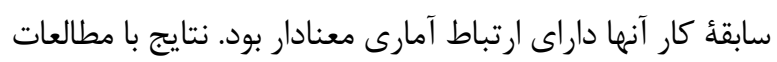
Mayel Afshar عنوان "ابررسى تأثير ويزگى هاى جمعيتشناختى بر رفتار شهروندى سازمانى كاركنان بيمارستانهاى آموزشى منتخب

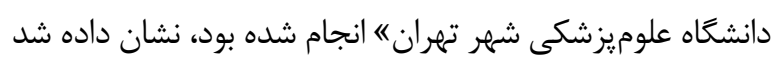
كه با افزايش سن و سابقـ كارى، ميزان رفتار شهروندى سازمانى

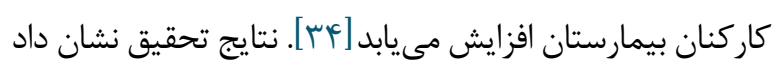
رفتار شهروندى سازمانى تفاوت معنادارى با وضعيت تأهل، سطح

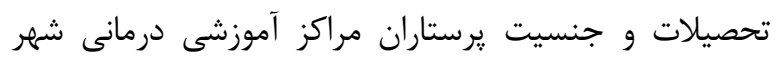

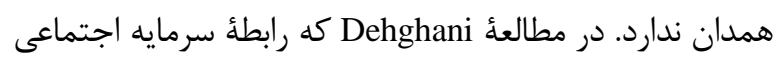

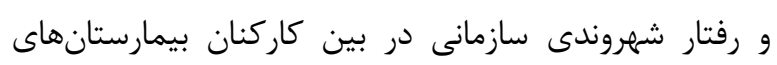

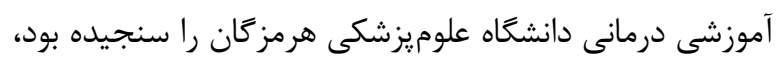
رفتار شهروندى سازمانى اين كاركنان با وضعيت تأهل و جنسيت درماني 


$$
\text { منابع مالى مالى اين مطالعه توسط نويسندگان تامين شده است. }
$$

\section{References}

1. MoradiChaleshtari MR, Jafari A. Relationship between organizational justice and organizational citizenship behaviors in Physical Education Organization of Islamic Republic of Iran. Journal of Olympics. 2012; 1(53):14556. [In Persian]

2. Muenjohn N, Armstrong A. Evaluating the Structural Validity of the Multifactor Leadership Questionnaire (MLQ), Capturing the Leadership Factors of Transformational-Transactional Leadership. Contemporary Management Research. 2008; 4(1):3-14. [DOI:10.7903/cmr.704]

3. Saiedjavadin S, Abedi E, Yazdani H, Pourvali B. Investigate the mediating role of trust and commitment in the relationship between organizational justice and organizational citizenship behavior in hospitals. Journal of Business Management. 2013; 5(1):105-18 [In Persian]

4. Azami H, Khaledi Paveh B, Rezaei M, Samadzadeh S. The impacts of short-term foot massage on mean arterial pressure of neurosurgical patients hospitalized in intensive care units. Iranian Journal of Critical Care Nursing. 2015; 8(3):133-42.

5. Farhadian T. A Study of Leadership Styles of Nurses Working in Hospitals Affiliated with Iran University of Medical Sciences . Applied Studies in Management and Development Science. 3(11), 2017. 51-54 [In Persian]

6. Sedighiani E. Organization and hospital management. Tehran: Nashre electronici va etela resani jahan rayaneh. 1998.

7. Sadeghi A, Maleki Jamasbi M, Hasanian M, Karami M. Relationship between Head Nurses' Leadership Style and Nurses' Organizational Citizenship Behavior. Journal of Clinical Research in Paramedical Sciences. 2017; 5(4):371-80.

8. Hui C, Schaubroeck J. Can good citizens lead the way in providing quality service? Academy of Management Journal. 2001; 44(5):988-95. https://doi.org/10.5465/3069442 [DOI: $10.2307 / 3069442]$

9. Sarmad S. Study of the effect of internal marketing on market-orientation and service organizations' performance (Case study: Branches of Refah Bank in City of Arak). Journal Journal Of Marketing Management. 2013; 8(18):91-106.

10. Bolino M. Going the extra mile: cultivating and managing employee citizenship behavior. Academy of Management Executive. 2003; [DOI:10.5465/ame.2003.10954754]

17(3):60-71.

11. Altuntas S. Relationship between nurses' organizational trust levels and their organizational citizenship behaviors. Journal of Nursing Scholarship. 2010; 42(2):186-94. [DOI:10.1111/j.1547-5069.2010.01347.x] [PMID]

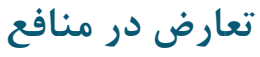 \\ بين نويسندگان هيجزَّنه تعارضى در منافع وجود ندارد
}

12. Mohamadi SM, Majidi K. Organizational citizenship behavior and leadership styles. Boushehr Danesh Entezami. 2012; 3(8):21-41.

13. Sadeghi A, Adeli Z, Shamsaei F, Moghim Beigi A. Relationship between nurses' moral intelligence and patients' satisfaction from nursing care. Quarterly Journal of Nursing Management. 2015; 4(3):65-76.

14. Ebrahimpour H, Janalizade Cobasti M, Dehqani AR. The relationship between leadership style and organizational citizenship behavior as a factor of organizational entrepreneurial behavior towards entrepreneurship (The study of Agriculture Organization of Qom). Paper presented at The National Conference on Entrepreneurship And Business Management Knowledge. 4/10/91, Babolsar, Iran.

15. Tsai Y. The relationships between organisational citizenship behaviour, job satisfaction and turnover intention. Journal of Clinical Nursing. . 2010; 19(2324):3564-74. [DOI:10.1111/j.1365-2702.2010.03375.x] [PMID]

16. Barroso Castro C, Martín Ruiz D. The influence of employee organizational citizenship behavior on customer loyalty. International Journal of Service Industry Management. 2014; 15(1):27-53. [DOI:10.1108/09564230410523321]

17. Safavi M, Yahyavi H, Farahani H, Radfar F. Descriptions and correlation of organizational citizenship behaviors with perceived procedural justice of nurses employed in hospitals affiliated to Tehran University of Medical Sciences. Journal of Medical Sciences, Islamic Azad University. 2014; 24(1):43-8.

18. Tamunomiebi MD, Onah GO. Organizational citizenship behaviour: A critical review of its development in a diversity driven workplace. The Strategic Journal of Business \& Change Management. 2019; 6(1):41-60.

19. Podsakoff PM, Moorman RH, Fetter R. Transformational leader behaviors and their effects on followers' trust in leader, satisfaction, and organizational citizenship behaviors. The Leadership Quarterly. 1990; 1(2):107-42. [DOI:10.1016/1048-9843(90)90009-7]

20. The Simple And Multiple Relationships Of The Organizational Justice With Organizational Citizenship Behavior In The Employees Of An Industerial Organization In Ahvaz. Journal of Educational Sciences and Psychology.Spring 2006, 13(1):79-92. [In Persian]

21. Fuladvandi M, Tofighi M, Fuladvandi GR, Ramezani M. The relationship between job satisfaction and organizational citizenship behavior: a study on nurses working in intensive care units and emergency departments of hospitals affiliated to Kerman University of Medical Sciences in 2012. Health Development Journal. 2014; 3(4):341. 
22. Navid Hamidi M, Emamzadeh Ghasemi H, Hajrajabi A, Esmaeili Givi S. Relationship between ethical climate and organizational citizenship behaviors among of nurses in intensive care units. Quarterly Journal of Nursing $\begin{array}{llll}\text { Management. 2017; 6(2):51-9. [In Persian] } & \end{array}$ [DOI:10.29252/ijnv.6.2.51]

23. Bahrami M, Salehi M, Dehghani Tafti A, kiyani M, Entezarian Ardekani S. The study of nurses' organizational citizenship behavior at Yazd's selected teaching hospitals in 2015. Journal of Jiroft University of Medical Sciences. 2016; 2(2):174-82.

24. Dehghani M, Hayavi Haghighi MH, Estebsary F, Rafati S, Khorami F. The relationship between social capital and organizational citizenship behavior among teaching hospitals staff at Hormozgan Univercity of Medical Sciences. Journal of Modern Medical Information Sciences. 2015; 1(1):24-32.

25. Nourani Saadoldin S, Esmaily H, Hooshmand E. The relationship between organizational citizenship behavior, job satisfaction, and occupational stress among midwives working in healthcare centers of Mashhad, Iran, 2014. Journal of Midwifery and Reproductive Health. 2016; 4(2):622-30.

26. ZareiMatin H, Ahmadi F. A comprehensive model for identifying factors impacting on development of organizational citizenship behavior. African Journal of Business Management. 2010; 4(10):1932.

27. Tabarsa G, Esmaeili Givi HR. Effective factors on organizational citizenship behavior in a military hospital. Journal of Military Medicine. 2010; 12(2):93-9.

28. Guangling W. The study on relationship between employees' sense of organizational justice and organizational citizenship behavior in private enterprises. $\begin{array}{lll}\text { Energy } & \text { Procedia. 2011; } & \end{array}$ [DOI:10.1016/j.egypro.2011.03.350]

29. Walumbwa FO, Orwa B. Contingent reward transactional leadership, work attitudes, and organizational citizenship behavior: The role of procedural justice climate perceptions and strength. The Leadership Quarterly. 2008; 19(3): 251-60. [DOI:10.1016/j.leaqua.2008.03.004]

30. Maleki Nia E, Sadeghi M. Investigating the status of organizational citizenship behavior in employees of Razi University of Kermanshah. Paper presented at The First National Conference on Organizational Citizenship Behavior. 20/1/2009; Tehran, Iran.

31. Moghimi SM. Organizational citizenship behavior from theory to practice. Journal of Management Culture. 2005; 11:19-48.

32. Podsakoff PM, MacKenzie SB. Impact of Organizational Citizenship Behavior on Organizational Performance: A Review and Suggestion for Future Research. Human Performance. $1997 \quad$ 1997/06/01;10(2):133-51. [DOI:10.1207/s15327043hup1002_5]

33. Judge TA. Essentials of organizational behavior. London: Pearson; 2015.

34. Mayel Afshar M, Pourreza A, MemarPour M. Surveying the effect of demographic specification on organizational citizenship behavior of staff of selected educatioanl hospitals of Tehran Universities of Medical Sciences. Journal of Hospital. 2013 Sep 15;12(2):51-62. [In Persian].

35. Azim Zadeh SM, Asadi H. Determining the relationship between organizational citizenship behavior and personality and the role of moderating demographic variables. Sports Management Journal. 2013; 4:27-42. [In Persian].

36. Dargahi H. The relationship of organizational citizenship behavior with job satisfaction and organizational commitment of nurses among public hospitals of Tehran University of Medical Sciences. Management Strategies in Health System. 2017; 2(3):234-46.

37. Moradzade S, Abedi MR, Siadat SA. A study of the multiple relationships between organizational citizenship and life satisfaction of employees at the University of Isfahan. Journal of Applied Sociology. 2014; 24(4):10318. [In Persian].

38. Raeisi A, Jafarian $H$. Investigating the relationship between self-esteem and organizational citizenship behavior (case study of police officers of Bushehr province). Quarterly Journal of Bushehr Law Enforcement. 2014; 15(4):49-67. [In Persian].

39. Yousefi Amiri M, Gholipour A, Seyyed Javadin S, Vakili M. Relationship between personality traits of nurses with organizational citizenship behavior in Zanjan Educational Hospitals, 2012. Preventive Care in Nursing and Midwifery Journal. 2013-2014; 3(2):70-80.

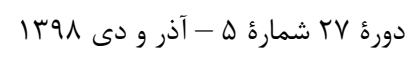

